\title{
ABORDAGEM PELO UROLOGISTA DA SEXUALIDADE NO LESADO RAQUIMEDULAR ${ }^{1}$
}

\author{
MANAGEMENT OF SEXUALITY OF PATIENTS \\ WITH SPINAL TRAUMA BY THE UROLOGIST
}

\author{
Haylton Jorge Suaid ${ }^{2}$ \\ Jeová Nina Rocha ${ }^{2}$ \\ Antonio Carlos Pereira Martins ${ }^{3}$ \\ Adauto José Cologna ${ }^{2}$ \\ Carla A Suaid ${ }^{4}$ \\ Ana Gabriela B Ribeiro ${ }^{4}$ \\ Patrícia L Salzedas $^{5}$
}

\section{RESUMO}

Os autores enfatizam a necessidade do médico urologista, que faz atendimento do paciente lesado raquimedular com disfunção genitourinária, ter atenção também ao aspecto da sexualidade do paciente. A orientação deve ser voltada para a reabilitação sexual através da busca da exitação, da procura de áreas erógenas no corpo e a resposta ao desejo sexual.

Descritores - lesão raquimedular; bexiga neurogênica; sexualidade. Disponível em URL: http://www.scielo.br/acb

\begin{abstract}
The authors address to urologists who manage patients with spinal trauma and urinary tract dysfunction on the importance to pay attention also to patients' sexuality. Sexual activity recovery should be pursued through the search of erotic areas, excitement and response to the sexual desire.
\end{abstract} sexuality

Key Words - spinal trauma, neurogenic bladder,

\section{INTRODUÇÃO}

Durante muitos anos, profissionais de saúde que cuidavam de pacientes portadores de lesão raquimedular só se preocupavam com o restabelecimento da saúde e recuperação da função motora. Posteriormente, observou-se que as necessidades desses pacientes não deveriam se limitar exclusivamente a tais cuidados, mas também levar em consideração um processo de educação, aconselhamento e reabilitação. A partir dessa constatação, como também da solicitação dos pacientes por atenção a este aspecto, surgiu um interesse por parte dos profissionais em lidar, inclusive, com a questão da sexualidade. De início, verificou-se que esses profissionais não tinham o preparo ou qualificação especializada, sendo necessário, portanto, em um primeiro momento, a aquisição de uma base teórica, revisão de valores e crenças, para assim poderem alcançar os objetivos propostos.

Além da falta de profissionais qualificados, constatou-se ademais que existem apenas alguns poucos centros que oferecem um programa de orientação sexual. Mesmo assim, apurou-se que os profissionais que atuam nesses centros o fazem de forma isolada, procurando atender apenas às necessidades imediatas dos seus pacientes.

Dessa forma, o objetivo dessa revisão foi levantar o problema das complicações do trato genitourinário decorrentes da lesão raquimedular, particularmente em relação à reabilitação sexual e sexualidade.

1 Trabalho realizado pela Disciplina de Urologia do Hospital das Clínicas da Faculdade de Medicina de Ribeirão Preto - USP

2 Prof. Dr Assoc. da Disciplina de Urologia do Departamento de Cirurgia e Anatomia - FMRP-USP

3 Prof. Titular da Disciplina de Urologia do Departamento de Cirurgia e Anatomia - FMRP - USP.

4 Fisioterapêuta voluntária junto ao Setor de Urodinâmica do HCFMRP-USP

5 Psicóloga do Deparrtamento de Neuropsiquiatria - FMRP - USP 


\section{Lesão Raquimedular}

A lesão raquimedular tem afetado preponderantemente pessoas do sexo masculino, na sua grande maioria jovens, econômica e sexualmente ativas antes da lesão, provavelmente por estarem mais expostas a várias situações de risco e violência ${ }^{1,2,3}$. Um estudo retrospectivo em 428 prontuários feito no Instituto de Ortopedia e Traumatologia do Hospital das Clínicas da Faculdade de Medicina da Universidade de São Paulo sobre a lesão raquimedular, no período de 1982 a 1987 , mostrou uma incidência de $91,8 \%$ em indivíduos do sexo masculino. Percentual semelhante foi encontrado por outros autores ${ }^{4,5}$. Em relação à faixa etária daqueles pacientes, foi constatado uma incidência percentual de $24,2 \%$ entre indivíduos de 11 e 20 anos, de $34,9 \%$ entre 21 e 30 anos, de $20,1 \%$ entre 31 e 40 anos e de $11,4 \%$ entre 41 e 50 anos $^{6}$.

A intensidade das lesões pode variar de leves até lesões mais graves, completas ou incompletas, isto é, lesões completas em que as funções motoras encontram-se totalmente interrompidas abaixo do nível do trauma, e as lesões incompletas em que se encontra preservada alguma função motora e/ou sensitiva abaixo da lesão.

Assim, é importante enfatizar, que o grau de disfunção orgânica e sexual está diretamente relacionado com o nível, a extensão da lesão, e o tempo pós-lesãoo ${ }^{7,8,9}$. No entanto, considera-se que a lesão raquimedular não leva necessariamente à perda da sexualidade. É consenso que a sexualidade não se perde com uma lesão ou doença. Toda pessoa, qualquer que seja o seu sexo, continua sendo um ser sexuado. As alterações motoras, sensitivas e autônomas podem desencadear alterações no complexo mecanismo neuro-psico-endócrinovascular, e esse fato pode dar lugar a uma disfunção sexual. A partir dessas alterações, poderiam ocorrer dois tipos de disfunção sexual, a primária quando originária de alterações orgânicas, e a disfunção sexual secundária, ser proveniente de mudanças comportamentai ${ }^{10}$.

A atuação urológica junto a pacientes lesados raquimedulares é muito mais relacionada à prevenção de problemas físicos e biológicos, conseqüentes da lesão, dentre eles as úlceras cutâneas (escaras), o cateterismo vesical intermitente, a infecção do trato urinário e obstipação intestinal crônica. Observa-se que a falta de um programa sistemático, voltado para uma orientação sexual, faz com que os pacientes portadores dessa patologia recebam esclarecimentos ou orientações como um procedimento complementar nãosistematizado, isolado, fragmentado, dizendo que a parte da sexualidade será tratada em momento oportuno, ou então:
Vamos tentar resolver primeiro a sua infecção urinária; posteriormente nos preocuparemos com o seu problema de sexo.

Tal postura revela claramente uma atitude de fuga por parte do profissional em encaminhar o problema daquele indivíduo de forma correta.

Assim, o urologista deve abordar o tema da sexualidade no setor de bexiga neurogênica e lesado medular de forma sistematizada, natural, simples e direta, perguntando ao paciente isoladamente ou ao casal, sobre a sua vida sexual, os seus desejos e como são expressos os seus sentimentos. Neste contexto não é infrequente deparar-se com ditos como:

Mas, ela precisa de um colchão d'água e fica muito ruim para os dois. Ela não deve sentir mais "nada". Ela perdeu a sensibilidade nas pernas. Eu tenho medo de machucá-la por causa da situação dela. Nós perdemos o interesse em fazer sexo...

A orientação do casal sobre a retomada de sua vida sexual e possíveis procedimentos de tratamento, implicam por parte do profissional que os atende um domínio básico do ato sexual na sua dimensão física. Para uma boa orientação dos pacientes, o profissional deve ter plena convicção de que a deficiência física não neutraliza a sexualidade, acreditar que a função sexual é parte integral da vida de uma pessoa e que seu exercício rejuvenesce o ego. É importante realçar que o processo da resposta sexual pode ocorrer em fases que são identificadas como a do desejo ou exitação, platô, orgasmo e final ou de resolução ${ }^{11}$. A fase do desejo é de origem central e pode ser caracterizada como psicogênica e pode desencadear as fases seguintes. Nessa fase são fundamentais o componente erótico e a integridade física, ocorrendo a lubrificação vaginal e a ereção. É importante realçar que, além das áreas genitais há regiões erógenas no corpo que mantêm ou ajudam no processo de exitação. São essas áreas que devem ser identificadas e exploradas pelo parceiro(a), pois a expressão sexual é versátil e cada pessoa deve descobrir o tipo que mais a atrai e o melhor modo de conseguí-la.

Assim, é fundamental que o urologista que faz atendimento de pacientes com lesões raquimedulares também procure dar a orientação sexual a esses pacientes com a intenção de melhorar a qualidade de vida.

\section{REFERÊNCIAS}

1. Stover SL, Fine PR. The epidemiology and economics of spinal cord injury. Paraplegia 1987;25:225-8.

2. Harvey C, Tothschild BB, Asmann AJ, Stripling T. New stimate of traumatic SCIK prevalence: a survey-based approach. Paraplegia 1990;28:537. 
3. Salmene ACM. Sexo: Caminho para a Reabilitação (ed) Cortez Editora. 1995. p. 64.

4. Barros Filho TEP. Revista Hospital das Clinicas de S. Paulo Faculdade de Medicina da Universidade de S. Paulo 1990;45(3):123-6.

5. Santos LRC. Lesão Traumática da Medula Espinhal. Estudo Retrospectivo de Pacientes Internados no Instituto de Ortopedia e Traumatologia do Hospital das Clínicas da Faculdade de Medicina da Universidade de S. Paulo entre 1982 e 1987. Dissertação de Mestrado apresentada à E.E. - USP. 1989. p. 102.

6. Master W, Johnson V. A Resposta Sexual Humana. São Paulo. Livraria Roca. 1986.

7. Salmene ACM. Sexo: Caminho para a Reabilitação (ed) Cortez Editora. 1995. p. 64.

8. Comarr AE. Sexual function among patients with spinal cord injury. Urol Int 1970;25:134-68.

9. Talbot HS. The sexual function in paraplegics. J Urol 1975; 73:95.
10. Casalis MEP. Sexualidade no Paciente Paraplégico. In: Aplicação Clínica de Urodinâmica. Carlos D'Ancona e Nelson Rodrigues Netto Jr. (Ed) Cartgraf Editora Ltda. Campinas - SP. 1996. p. 295

11. Yalla V, Vickers Jr Ma, Sullivan Mp, Sarkarati M. Sexual Dysfunction and Spinal Cord Injury. In: Bennett, A. H (Ed) Impotence, Diagnosis and Management of erectile Dysfunction, W.B. Saunders Company. London. 1994. p.175-85

\section{Endereço para correspondência}

Haylton Jorge Suaid

Hospital das Clinicas da FMRP-USP;

Departamento de Cirurgia,

Av. Bandeirantes, 3900, Ribeirão Preto, SP,

CEP- 14048-900

e-mail: hjsuaid@fmrp.usp.br 